\title{
QUEEN'S
UNIVERSITY
BELFAST
}

\section{The impact of channel fill level on internal forces during continuous twin screw wet granulation}

Mendez Torrecillas, C., Gorringe , L., Rajoub , N., Robertson, J., Elkes , R., Lamprou, D., \& Halbert, G. W. (2018). The impact of channel fill level on internal forces during continuous twin screw wet granulation. International Journal of Pharmaceutics, 91-100. https://doi.org/10.1016/j.ijpharm.2018.12.052

\section{Published in:}

International Journal of Pharmaceutics

\section{Document Version:}

Peer reviewed version

\section{Queen's University Belfast - Research Portal:}

Link to publication record in Queen's University Belfast Research Portal

\section{Publisher rights}

Copyright 2018 Elsevier.

This manuscript is distributed under a Creative Commons Attribution-NonCommercial-NoDerivs License

(https://creativecommons.org/licenses/by-nc-nd/4.0/), which permits distribution and reproduction for non-commercial purposes, provided the author and source are cited.

\section{General rights}

Copyright for the publications made accessible via the Queen's University Belfast Research Portal is retained by the author(s) and / or other copyright owners and it is a condition of accessing these publications that users recognise and abide by the legal requirements associated with these rights.

Take down policy

The Research Portal is Queen's institutional repository that provides access to Queen's research output. Every effort has been made to ensure that content in the Research Portal does not infringe any person's rights, or applicable UK laws. If you discover content in the Research Portal that you believe breaches copyright or violates any law, please contact openaccess@qub.ac.uk. 
International Journal of Pharmaceutics

1 The impact of channel fill level on internal forces during continuous twin

2 screw wet granulation.

3 Carlota Mendez Torrecillas ${ }^{1,2}$, Lee J. Gorringe ${ }^{3}$, Nazer Rajoub ${ }^{1,2}$, John Robertson ${ }^{1,2}$,

4 Richard G. Elkes ${ }^{3}$, Dimitrios A. Lamprou ${ }^{4}$, Gavin W. Halbert ${ }^{1,2^{* *}}$

51 EPSRC Centre for Innovative Manufacturing in Continuous Manufacturing and

6 Crystallisation (CMAC), University of Strathclyde, Technology and Innovation Centre, 99

7 George Street, G1 1RD Glasgow, United Kingdom.

$8{ }^{2}$ Strathclyde Institute of Pharmacy and Biomedical Sciences (SIPBS), University of

9 Strathclyde, 161 Cathedral Street, G4 0RE Glasgow, United Kingdom.

${ }^{3}$ R\&D Platform Technology \& Science GSK ,David Jack Centre for R\&D , Park Road, Ware,

11 Hertfordshire, SG12 0DP, United Kingdom

$12{ }^{4}$ School of Pharmacy, Queen's University Belfast, 97 Lisburn Road, BT9 7BL, United 13 Kingdom

** Funded by Cancer Research UK Formulation Unit

15 Corresponding authors: Carlota Mendez Torrecillas and Gavin W. Halbert.

Corresponding authors email: carlota.mendez@strath.ac.uk and g.w.halbert@strath.ac.uk.

Corresponding authors phone number: $+44(0) 1415482454$

Corresponding authors address: Strathclyde Institute of Pharmacy and Biomedical Sciences 
International Journal of Pharmaceutics

\section{ABSTRACT}

24 The forces experienced by the particles inside a twin screw granulator (TSG) are one of the 25 most difficult parameters to measure quantitatively. However, it is possible to perform 26 accurately this measurement through the use of dye containing calibrated microencapsulated 27 sensors (CAMES) whose rupture is directly dependant on their experienced shear stress. The current study measures the extent of local stresses in the transformation from powder to granules at different channel fills during TSG processing. Channel fill has shown good potential as a design tool, however, its validity for predicting particle size distributions has yet to be demonstrated in an 11-mm TSG. The results of this study showed that the particles within the twin screw granulator experienced stresses in the range of $350-1000 \mathrm{kPa}$ and this value was not linear with the specific mechanical energy applied by the granulator. It was observed that the majority of these stresses were produced by material transport processes rather than the granulation in itself. In addition it was determined that the torque required by the TSG increases exponentially after a certain channel fill a feature that requires to be considered in order to design safer, predictable and reliable granulation workspaces.

Keywords: Twin screw granulation, Design space, Stress, Channel fill level, Particle size distribution, Continuous wet granulation 
International Journal of Pharmaceutics

\section{ABBREVIATIONS}

$41 \quad \mathrm{~B} \%$

Percentage of broken sensors

42 CAMES Calibrated Microencapsulated sensors

$43 \quad \mathrm{C}_{\mathrm{eq}}$

Standardised concentration

$44 \quad \mathrm{C}_{\mathrm{i}}$

Initial concentration

$45 \quad \mathrm{C}_{100 \%}$

$100 \%$ rupture of sensors concentration.

$46 \quad \mathrm{C}_{\text {stock }}$

Concentration of the stock solution

$47 \quad \mathrm{~d} 10$

Intercept 10 of the particle cumulative distribution

$48 \quad \mathrm{~F}$

Powder feed rate $(\mathrm{kg} / \mathrm{hr})$

$49 \mathrm{~L} / \mathrm{S}$

Liquid-to-solid ratio

$50 \quad \mathrm{~L} / \mathrm{D}$

Length to Diameter ratio

$51 \quad m_{i}$

Sample mass $(\mathrm{g})$

$52 \dot{\mathrm{m}}$

Powder flowrate

$53 \mathrm{n}$

Number of repetitions

$54 \mathrm{~N}$

Screws velocity

$55 \mathrm{n}_{\mathrm{v}}$

Volumetric efficiency of the conveyor

$56 \quad$ PSD

Particle Size Distribution

$57 \quad \mathrm{R} 2$

Coefficient of determination

$58 \mathrm{UV}$

Ultraviolet

$59 \quad V_{F}$

Conveyor free volume 
International Journal of Pharmaceutics

60 VMD Volume mean diameter

61 SME Specific Mechanical Energy

$62 \mathrm{~T} \quad$ Torque

63 TSG Twin-Screw Granulator

$64 \Delta \Phi \quad$ Difference of channel fill

$65 \Phi \quad$ Channel fill fraction

$66 \sigma_{\text {CAMES }} \quad$ Shear stress calculated by the calibrated CAMES

67 
International Journal of Pharmaceutics

\section{INTRODUCTION}

Granulation is a common industrial operation for particle size enlargement, which traditionally has been performed in batch based operations. Continuous granulation processes which offer advantages such as improved quality, rapid API sparing development and greater flexibility have driven interest to shift towards continuous operation. Continuous granulation not only offers the probability of enhanced product quality it also simplifies and reduces risk in the development process by using the same equipment in both development and production processes (Keleb et al., 2002; Van Melkebeke et al., 2008).

One of the common equipment items evaluated to perform continuous granulation are the twin screw granulators (TSGs) (Mundozah et al., 2018; Silva et al., 2018). The advantage of this equipment is the flexibility offered from the high number of possible working environments achieved by changing different sections of the screw assembly, different segment geometries or feed port locations (Dhenge et al., 2011; Djuric and Kleinebudde, 2008). Even within a constant screw and barrel configuration, a wide range of different outputs can be obtained by varying conditions such as feed rate or liquid/solid ratio (Mendez Torrecillas et al., 2017; Thompson, 2014). However, the current state of art of this technology leads to a high experimental burden that does not yet allow the full realisation of the anticipated acceleration and active pharmaceutical ingredient (API) savings in pharmaceutical development process.

The establishment of a flexible design space based on scale independent approaches would have value in setting process control strategies as well as being advantageous during the product lifecycle when the throughput of the process can be varied on demand. This requires an increased knowledge of the granule properties as function of the process parameters. Also, it is required to determine the acceptable working limits and conditions of the TSG equipment. 
International Journal of Pharmaceutics

91 Previous studies have shown the capability of channel fill level as a main parameter to establish

92

93

94

95 the design space (Gorringe et al., 2017; Lute et al., 2018; Osorio et al., 2017). This is normally referred as the total fraction occupied by powder and granules with respect to the full volume of the granulator (Gorringe et al., 2017; Lee et al., 2012). It depends on four factors: screw configuration, length to diameter ratio of the granulator, feed rate and screw velocity. The first two parameters are fixed properties during operation opposite to feed rate and screw velocity which are process variables (Seem et al., 2015). Both parameters have been extensively studied in the literature separately or combined where screw speed has been reported to have a minor influence on the granules properties compared with feed rate (Dhenge et al., 2011; Dhenge et al., 2010; Djuric and Kleinebudde, 2008; Keleb et al., 2004; Thompson and Sun, 2010). The screw velocity is inversely proportional to the channel fill obtaining higher channel fills for lower screw speeds. At the same time, increase in the feed rate, will increase the channel fill. Those two process variables together have a direct effect in the compaction forces applied to the wetted mass (Thompson and Sun, 2010). When the granulator is at low fill, there is a reduction in the compaction force and more friable and porous granules are therefore produced (Lee et al., 2012). Different equations for barrel fill have been defined having the use of feed rate and screw velocity in common (Gorringe et al., 2017, Osorio et al., 2017). On one side, Gorringe et al. used the fraction of the capacity of the twin screw granulator which facilitates the direct transfer to production lines from research phases. However, it does not take into account changes of screw configuration which limits the transfer to different assemblies (Gorringe et al., 2017). On the other side, Osorio et al. used the powder feed number to calculate this value where changes in configuration are considered. However, the calculation requires high technical knowledge of the equipment since parameters such as the cross-sectional area of the elements or net forward velocity of the powder need to be known (Osorio et al., 2017). Nevertheless, both studies have shown the capability of channel fill level 
International Journal of Pharmaceutics

as a main parameter to establish the design space. Channel fill fraction correlates strongly with the granule attributes within same scale obtaining very similar granule size distributions for runs at the same fraction at the same TSG scale (Gorringe et al., 2017, Lute et al., 2018, Osorio et al., 2017).

Despite the potential of channel fill as a design tool, there is not an extensive knowledge base indicating how the increase of channel fill affects the process within the TSG. Some studies have already suggested there are inner variations due to the change in shape of the granules. High channel fills have been associated with more spherical products, whereas low channel fills have been reported to produce more elongated granules for the 16-mm TSG (Dhenge et al., 2011; Gorringe et al., 2017). However, Verstraeten et al. concluded that the process settings on a $25-\mathrm{mm}$ TSG had minimum influence on the final shape of the granules whereby it is dictated by the restricted volume of the kneading elements compartment (Verstraeten et al., 2017). A considerable difference in some properties has also been reported for the same feed rates and screw speeds possessing different granulators or scale (Djuric et al., 2009; Osorio et al., 2017). Therefore, changes in granule morphology seem to indicate that changes in the local forces inside the granulator are dependent on both TSG scale and process settings. In any case, there are few examples of quantitative studies of the mechanical stresses in the screw elements. Traditionally, the stresses experienced by the granules in the TSG have been calculated at a global level as direct function of the torque applied by the granulator (Dhenge et al., 2012) or as function of the screw speed (Lute et al., 2018).

Pradhan et al. measured the breakage at different type of screw elements with pellets of ballotini glass beads mixed with liquid binder of known dynamic yield strength (up to $160 \mathrm{Kpa}$ ) and size. It was concluded that the breakage of the pellets was dependant on the available gap size of the screw elements. When pellets were larger than the available gap size, they appeared completely broken. Whereas, those smaller than the gap size were dependent upon their 
International Journal of Pharmaceutics

141

142

143

144

145

146

147

148

149

150

151

152

153

154

155

156

157

158

159

160

161

162

163

164

dynamic yield strength. For the $16 \mathrm{~mm}-\mathrm{TSG}$, they determined that the maximum size of granule which will remain unbroken was $3.49 \mathrm{~mm}$ for conveyor elements and $3.18 \mathrm{~mm}$ for distributive mixing elements. In addition, pellets under the limit showed a constant breakage probability of $20 \%$ which is independent of their yield strength (Pradhan et al., 2017). Other studies for the same scale measured the total stress indirectly depending on the torque and the volume of solid where the suggested stress acting on the material varied between 73 and 106 $\mathrm{kPa}$ (Dhenge et al., 2012). Although those results are not directly comparable due to change of scale, screw configuration and formulation, they give an indication of the order of magnitude of the stresses experienced by the granules.

The local stress applied to the granules can be measured directly by the use of microencapsulated sensor particles (CAMES), calibrated to rupture at specific critical stress levels releasing a dye which can be measured spectrophotometrically. Therefore, it is possible to have an accurate measurement of the total stresses exposed to a sample during its production. These stress sensitive beads have already been used before in continuous extrusion obtaining insight into the stress history of a hot melt extruder (Bigio et al., 2011; Pappas et al., 2012). CAMES are sized equivalent to the powder input so they provide information at the correct scale of scrutiny. This size characteristic will provide a more representative value than previous attempts where the sensors were not at the same scale as the powder and therefore experienced the inherent restrictions within channel of TSG.

Due to changes of density during the granulation, this study will compare the results depending on the total force applied by the granulator for unit of mass. This parameter is known as specific mechanical energy (SME) (Dhenge et al., 2013; Vercruysse et al., 2015) and it will provide an insight into global energy input /torque and help to understand the forces and loads acting on particles and how these change. 
International Journal of Pharmaceutics

165 In addition to the local mechanical stresses and channel fill, it is necessary to understand the 166 relationship between channel fill fraction and torque used by the equipment. Increasing the 167 transported amount of powder along the equipment would have a direct influence in the torque 168 required. This study attempts to verify the applicability of the channel fill fraction to the 11$169 \mathrm{~mm}$ TSG as well as the transferability of the CAMES measurement from extrusion to 170 granulation. In addition, it will establish the relationship between the stress experienced by 171 the granules at different channel fills and torque requirements. 
International Journal of Pharmaceutics

173

174

175

176

177

178

179

180

181

182

183

184

185

186

187

188

189

190

191

192

193

194

195

\section{MATERIALS AND METHODS}

\subsection{Materials}

\subsubsection{Granulation}

The powder formulation contained 73.5\% w/w lactose monohydrate (PubChem CID: 104938, Pharmatose 200,DFE Pharma, IMCD UK Ltd, Sutton, Surrey, United Kingdom), 20\% w/w microcrystalline cellulose (PubChem CID: 14055602, Avicel PH101, Sigma-Aldrich Company Ltd., Dorset, England), 5\% w/w hypromellose (PubChem CID: 57503849,Pharmacoat 603, Shin-Etsu Chemical Co. Ltd, Wiesbaden, Germany) and 1.5\% w/w croscarmellose sodium (PubChem CID: 6328154, Ac-Di-Sol, Danisco, Copenhagen, Denmark). The formulation was blended in batches of $5 \mathrm{~kg}$ in a 15L blender bin for 10 minutes at $17 \mathrm{rpm}$ in a Agiblend AB015 (Pharmatech, Coleshill, United Kingdom). Granulating liquid was distilled water (EMD Millipore $^{\mathrm{TM}}$ Pure Water Reservoirs, Millipore SAS, Mosheim, France) which was maintained at a liquid-to-solid ratio of 0.175 in weight. The volumetric mean diameter of the formulation was $71.54 \mu \mathrm{m}$ with a homogeneity factor of the PSD (Mendez Torrecillas, 2017) of 69.9\%.

\subsubsection{Mechanical stress measurement}

In order to measure the local mechanical stress, microencapsulated chemical sensors $\left(\mathrm{CAMES}^{\mathrm{TM}}\right.$, Mach I, Inc., Pennsylvania, USA) were used. These microcapsules (diameter < $44 \mu \mathrm{m})$ contain an organic UV detectable blue dye in xylene encapsulated in a polymeric sphere with rupture determined by the applied shear stresses (Condo and Kosowski, 1991). In this case, the rupture and shear stress are related linearly in a range of 231.75 to $1224.25 \mathrm{kPa}$ (0-100\% breakage). The blue dye is an anthraquinone (Automate ${ }^{\mathrm{TM}}$ Blue $8 \mathrm{AHF}$, Keystone Inc, Chicago, USA) which is fully soluble in IPA (2-Propanol, $\geq 99.8 \%$, HiPerSolv CHROMANORM® for HPLC, VWR International Limited, Lutterworth, United Kingdom) 
International Journal of Pharmaceutics

196

197

198

199

200

201

202

203

204

205

206

207

208

209

210

211

212

213

214

215

216

217

with $\lambda \max$ of $645.77 \mathrm{~nm}$. The sensors were added to $125 \mathrm{~g}$ batches of the formulation in a proportion of $0.53 \% \mathrm{w} / \mathrm{w}$ and mixed in 51 blender at $3 \mathrm{rpm}$ for $40 \mathrm{~min}$.

\subsection{Granulation experiments}

The experiments were carried out using a Thermofisher Pharma 11-mm Twin Screw Granulator (Process 11, 40:1 L/D, Thermo Fisher Scientific, Karlsruhe, Germany) operating a constant temperature of $20^{\circ} \mathrm{C}$ with a cooler thermostat (Eco RE630, LAUDA DR. R. WOBSER GMBH \& CO. KG, Lauda-Königshofen, Germany). The TSG was fed via a gravimetric feeder (Brabender Gravimetric feeder DDW-MT, Brabender Technologie Gmbh \& Co. Kg Duisburg, Germany) and the liquid added by a syringe pump to remain a constant Liquid-to-solid ratio of 0.175 (Harvard Syringe Pump, Harvard Apparatus UK, Cambridge, United Kingdom). The screw configuration consisted of 1 set of $9 \times 0.25 \mathrm{D}$ bilobe kneading element ( $60^{\circ}$ forward), $1 \times$ $0.25 \mathrm{D}$ distributive mixing element (DME), $3 \times 1 \mathrm{D}$ distributive feed screws (DFS) and the rest conveyors. Samples for analysis were taken when steady state was reached after 2.5 minutes which was over twice the maximum mean residence time. The residence time was calculated for all the conditions dividing the material hold-up of the equipment by the feed rate (Gorringe et al., 2017). Afterwards, the samples were dried for $2 \mathrm{~h}$ in an oven (Memmert UNB100, Memmert GmbH $+\mathrm{Co} . \mathrm{KG}$, Schwabach, Germany) at $60{ }^{\circ} \mathrm{C}$. This conditions ensured a final moisture under $1 \%$ in weight

The channel fill for the 11-mm TSG was studied using the summary of experiments which can be found in figure 1 where the points of measurements are represented. The channel fill $(\Phi)$ is calculated using equation 1 (Gorringe et al., 2017).

$$
\Phi=\frac{\dot{\mathrm{m}}}{n_{v} \rho_{B}\left(V_{F} \frac{S_{L}}{L}\right) N}
$$


International Journal of Pharmaceutics

219

220

221

222

223

224

225

226

227

228

229

230

231

232

233

234

235

236

237

238

239

240

241

242

Where $\dot{\mathrm{m}}$ is powder flowrate $(\mathrm{kg} / \mathrm{hr}), \mathrm{n}_{\mathrm{v}}$ is volumetric efficiency of the screw to convey powder which is assumed $100 \%, \rho_{\mathrm{B}}$ is the bulk density $\left(\mathrm{kg} / \mathrm{m}^{3}\right), \mathrm{V}_{\mathrm{F}}$ is the conveyor free volume considered $25.04 \mathrm{~cm}^{3}$ for this $11-\mathrm{mm}$ TSG, $\mathrm{S}_{\mathrm{L}} / \mathrm{L}$ is the inverse of length to diameter ratio of the TSG, i.e. inverse of 40:1 for the 11-mm TSG and N is the screws velocity (rpm).

Channel fill fraction was calculated based in bulk density since the liquid will be absorbed into the voids of bulk powder. Although, the profile of the parameter is difficult to determine experimentally due to changes within the granulator, mean bulk density can be assumed constant for a given liquid to solid ratio, screw configuration and formulation (Gorringe et al., 2017).

\subsection{Offline granule size analysis}

The analysis of the granule size distribution was performed using the QICPIC/RODOS L with vibratory feeder VIBRI/L (Sympatec GmbH System-Partikel-Technik, Clausthal-Zellerfeld, Germany). All the particle size distributions obtained were measured at 0.5 bar of primary pressure to avoid breakage of the granules during the analysis (MacLeod and Muller, 2012). The disperser conditions were optimised for each set of granules to obtain the optimal optical concentration of $0.5 \%$ during the particles measurement. All the particle size distributions (PSDs) were plotted in logarithmic scale of the volume mean diameter against the density distribution which were both calculated in accordance with ISO 13222-1:2014 (ISO 133221:2014, 2014). In order to compare if the PSDs are significantly equivalent, two methods were used depending on the number of experiments carried out for channel fill. For those cases under three experiments, F-test was used comparing the curves by the variance. This method tests the null hypothesis if the variances of two populations are equal (Brandt and Brandt, 2014; The MathWorks Inc, 2013). When three or more experiments were carried out, Anova with O'Brien homogeneity of variance assumption was used. This method will test if multiple data 
International Journal of Pharmaceutics

243

244

245

246

247

248

249

250

251

252

253

254

255

256

257

258

259

260

261

262

263

264

265

266

samples have equal variances, against the alternative that at least two of the data samples do not have equal variances (O'Brien, 1979; O'brien, 1981; The MathWorks Inc, 2013). This method was chosen because it does not take into account the shape of the population (Wang et al., 2017) as twin screw granulation produces polymodal PSDs shapes (Mendez Torrecillas et al., 2017). In addition, both methods were recommended when the length of the samples is smaller than 10 (Wang et al., 2017). All the analysis were performed using the software Matlab and Statistics Toolbox R2017a (The MathWorks, Inc., Natick, Massachusetts, United States) using each PSD as an individual level with a 0.05 significance level which is recommended for scientist data (Brandt and Brandt, 2014). The PSDs were compared also depending on the screw speed which will have a direct effect in the shear rate exerted on the powder mass (Lute et al., 2018). Three screw speeds were compared at three level of differences between channel fills (low: 0.108-0.147), medium (0.073-0.194) and high (0.046 -0.271).

\subsection{Calibration of the microencapsulated stress sensors}

\subsubsection{UV calibration}

To measure the microencapsulated stress sensor rupture a UV calibration relationship between absorbance and concentration, covering the possible range of rupture, was determined with ten systems, prepared gravimetrically (BP211D Analytical model, Sartorious, Surrey, United Kingdom), between $0-60$ ppm by weight. A concentrated dye provided by the manufacturer (Automate $^{\mathrm{TM}}$ Blue 8AHF, Keystone Inc, Chicago, USA) was weighted and solved in IPA obtaining three initial stock solutions of 115, 116 and $216 \mathrm{ppm}$. The concentrations were obtained to be gravimetrically within the measurement range of the weight scale. The dye was fully soluble in IPA and it was found to be fully mixed after 10 manual rotations. The subsequent solutions with concentrations between 0-60 ppmw were prepared by dissolving a specific volume of stock $\left(\mathrm{V}_{\text {stock}}\right)$ in IPA to reach a final total volume of $5 \mathrm{ml}$. The final 
International Journal of Pharmaceutics

267

268

269

270

271

272

273

274

275

276

277

278

279

280

281

282

283

284

285

286

287

288

concentrations were recalculated depending on the exactly weight added in order to increase the accuracy of the calibration. The absorbance was analysed in a UV Spectrometer (Carl Zeiss MCS600, Oberkochen, Germany) with offline cell holder attachment (Fibre-coupled cuvette holder of $10 \mathrm{~mm}$ cuvettes with UV Fiber Optics, Hellma GmbH \& Co, Müllheim, Germany). The calibration was repeated three times with an acceptance criteria of coefficient of regression $\left(\mathrm{R}^{2}\right)$ over 0.999 (figure 2).

\subsubsection{Dye recovery from the granules}

The study of a possible interference of the formulation in the measurement of released dye was investigated. The recovery of dye from both the blend and individual components of the blend was determined by adding $10 \mathrm{ml}$ of a $60 \mathrm{ppm}$ by weight dye-IPA solutions. The solutions were mixed with the blend and each of the individual components. Filtration was performed using a sample processing manifold (Biotage ${ }^{\circledR} \operatorname{VacMaster}^{\mathrm{TM}}$ 10, Biotage, Uppsala, Sweden) using syringe isolute single fritter reservoir filter $70 \mathrm{ml} 5 \mu \mathrm{m}$ (Biotage, Uppsala, Sweden) with smaller pore diameter than the $\mathrm{d} 10$ of the individual components particle size. Afterwards, monitored vacuum was applied by a vacuum controller (BUCHITM V-850, BÜCHI Labortechnik AG, Flawil, Switzerland). The dye solution recovered was analysed measuring the absorbance at the same wavelength of the UV calibration $(645.77 \mathrm{~nm})$.

After filtration dye recovery was between $98-101 \%$ which is inside of the variance range of the UV spectrometer and let us concluded that released dye can be fully recovered from the materials.

\subsubsection{Breakage of the microencapsulated stress sensors}

The shear stress which produces sensor rupture is calibrated for each lot by the manufacturer and the relationship between the shear stress and the percentage of rupture was shown to be linear (CAMES ${ }^{\mathrm{TM}}$ SENSORS Lot 9-13-553, Mach I, Inc., Pennsylvania, USA). The rupture 
International Journal of Pharmaceutics

291

292

293

294

295

296

297

298

299

300

301

302

303

304

305

306

307

308

309

310

311

312

313

of the CAMES with $<44 \mu \mathrm{m}$ was qualitatively confirmed by the use of shear cell rotor-stator integrated with a microscopic stage (Leica Microsystems (UK) Ltd, Milton Keynes, United Kingdom). The stage was adjusted to a gap distance between the rotor and stator discs to match the mean size of the sensors and spinning speeds range of 0.01 to $5 \mathrm{rad} / \mathrm{sec}$. In figure 3 , the shear stress over the sensors was increased by the increment of the velocity of the rotor. As it was expected, the CAMES break at the increase of shear stress.

In addition to determine quantitatively the absorbance of $100 \%$ sensor rupture the sensors were mixed with the blend in $0.53 \% \mathrm{w} / \mathrm{w}$ proportion and compressed in a manual hydraulic press (Specac Ltd., Orpington, United Kingdom) with a die of $0.8 \mathrm{~cm}$ applying a force over 7000 $\mathrm{kPa}$, which is higher than the maximum value indicated by the manufacturer. The fully broken capsules and the released dye were dissolved in IPA, filtered and their absorbance was analysed in UV. Five samples from different batches were analysed providing a concentration of 547.38 $\pm 69.73 \mathrm{ppm}_{\mathrm{w}}$ for the fully broken CAMES.

The granules obtained from the TSG were dissolved in 4-10 $\mathrm{ml}$ of IPA, filtered and the absorbance was measured in the UV. The amount of IPA varied in order to optimise the washing of the filter. The concentration was calculated using the dye-IPA calibration. Concentrations were standardised using equation 2 depending on the exact amount of IPA and filtered solid. Afterwards, standardised concentration was divided by the concentration given from a $100 \%$ rupture according to equation 3 . From that value is possible to calculate the shear stress using equation 4 which was provided by the manufacturer (MACH I Inc, Pensilvania, United States)..

$$
C_{e q}=C_{i} * \frac{1}{m_{i}} * \frac{1}{V_{i}}
$$

$$
B=\frac{C_{e}}{C_{100 \%}}
$$


International Journal of Pharmaceutics

Where $\mathrm{C}_{\mathrm{eq}}$ is the standardised concentration (ppm), $\mathrm{C}_{\mathrm{i}}$ is the concentration calculated from the absorbance $(\mathrm{ppm}), \mathrm{m}_{\mathrm{i}}$ is the mass of the sample $(\mathrm{g}), \mathrm{V}_{\mathrm{i}}$ is the volume of the sample $(\mathrm{ml}), \mathrm{B}$ is the percentage of broken sensors $(\%), \mathrm{C}_{100 \%}$ is the concentration when $100 \%$ of the sensors are broken, $\sigma_{\text {CAMES }}(\mathrm{kPa})$ is the shear stress calculated by the CAMES.

\subsection{Relationship between shear forces and channel fill in granulation}

Eight replicate granulations with CAMES and ten replicate granulations without them were carried out in the 11-mm TSG with a constant feed rate and L/S ratio but by varying the screw velocity between $40-400 \mathrm{rpm}$ (Table 1 ) in order to vary the torque as calculated by the equipment software. In addition, the same conditions were reproduced without liquid addition to study the effect of the granulation process on the torque. The results were compared with both torque and specific mechanical energy for the granulations without the CAMES. Formulation experiments were conducted thrice whereas a single repetition was carried out for were studied to investigate the variability of the specific mechanical energy at same channel fill.

In addition, the granulations with CAMES were used to compare the specific mechanical energy with total shear forces experienced by the granules. Samples of $0.5 \mathrm{~g}$ after reaching steady state were taken and analysed by the method explained in the previous section. The specific mechanical energy of the granulation was calculated by applying equation 5. (Dhenge et al., 2013; Godavarti and Karwe, 1997). 
International Journal of Pharmaceutics

336

337

338

339

340

341

342

343

344

345

346

347

348

349

350

351

352

353

354

355

356

357

358

Where SME is the specific mechanical energy $(\mathrm{kJ} / \mathrm{kg}), \mathrm{T}$ is the motor torque of the TSG $(\mathrm{N} . \mathrm{m})$,

$\mathrm{N}$ is the screws velocity (rpm) and $\mathrm{F}$ is the feed rate of the powder $(\mathrm{kg} / \mathrm{hr})$.

To study the relationship between local stress and channel fill, three channel fills were selected (low: 0.073, medium: 0.146 and high: 0.270 ) at two different velocities: 150 and $400 \mathrm{rpm}$ (Table 2). In order to isolate the impact of granulation from the conveyor transport of the powder, samples of 2 grams were taken for each run at the solid feeder exit and compared with the granules at the end of the twin screw granulator before and after the binder addition.

\section{RESULTS}

\subsection{Demonstration of 11-mm TSG channel fill scalability}

The potential of using channel fill to scale up feed rate was investigated verifying if this parameter can be used to predict PSDs in the 11-mm TSG. In figure 4, six different channel fills were investigated showing high similarity between their density distributions along a channel fill line independent of the screw velocity. The equivalence between the shapes of the PSDs is remarkable at low $(\Phi=0.046$ and $\Phi=0.073)$ and high $(\Phi=0.194$ and $\Phi=0.271)$ channel fills where at low channel fills fines are more prevalent than at high channel fills. One explanation for this behaviour is that the mean residence time and material hold-up increased for the same feed rate as function of the channel fill (Gorringe et al., 2017; Lee et al., 2012) which could reduce the contact between powder and therefore, the granulation rate.

However, the middle channels show more discrepancies between them. In both cases $(\Phi=0.108$ and $\Phi=0.147)$, two of the conditions presented very similar shapes and one of them was different. In order to compare statistically if the curves were significantly different, F-test and one way Anova with O'Brien homogeneity of variance assumption were performed depending on the number of experiments carried out for channel fill. In all the cases, it was 
International Journal of Pharmaceutics

359

360

361

362

363

364

365

366

367

368

369

370

371

372

373

374

375

376

377

378

379

380

381

382

concluded that at 0.05 level of tolerance, there were no significant differences between PSDs at the same channel fill (Table 3).

In figure 5, the PSDs were compared depending on the screw speed at three levels of difference of channel fill $(\Delta \Phi)$ : low (0.039), medium (0.121) and high (0.225). In this case, it is possible to observe that PSDs appeared significantly different at high level of difference of channel fill but this difference was not that significant when $\Delta \Phi$ was small. F-test statistical analysis was carried out (Table 4) for the PSDs and it confirmed that at low channel fill differences, the variation of channel fill is not significant. However as $\Delta \Phi$ increases, the difference in the PSDs increases too reaching a point at high levels of channel fills where the PSDs are not statically equivalent anymore. This suggests the inadequacy of using screw velocity as a design tool for predict PSDs this formulation.

\subsection{Relationship between channels fill and torque}

The channel fill effect on the torque required was studied at a constant feed rate of $0.5 \mathrm{~kg} / \mathrm{hr}$ and $\mathrm{L} / \mathrm{S}$ ratio and varying the screw velocity from 40 to $400 \mathrm{rpm}$ (Table 1 ). In figure 6 , the force required to both transport the powder with and without the addition of granulation fluid are presented. The torque necessary to move the powder when granulation takes place is nearly double than when powder is only transported. This phenomena can be associated with the changes of density due to the increased presence of formed granules and the resulting change in powder physical properties interacting with downstream elements. As well, the torque required at channel fills lower than 0.271 is relatively low in all the cases $(<1.5$ N.m) increasing slowly (green area). However, after that point, it increases sharply (red-coloured area). Gorringe et al. demonstrated that the material hold-up and the mean residence time inside the granulator are linear functions of the channel fill and increases considerably at low screw speeds (Gorringe et al., 2017). Therefore, this change in trend could be an indication 
International Journal of Pharmaceutics

383

384

385

386

387

388

389

390

391

392

393

394

395

396

397

398

399

400

401

402

403

404

405

that after reaching a certain point, the material hold-up within the equipment increased sharply at small variations.

For instance, in this region, a variation of $20 \mathrm{rpm}$ screw speed $( \pm 33.33 \%)$ at $60 \mathrm{rpm}(40-80$ rpm) will change the channel fill between 0.240 and 0.479 (equation 1) which will suddenly increase the torque from 1.8 to 3.2 N.m which supposes at $77.8 \%$ change. At the same time, a small variation of feed rate would produce the channel fill to fluctuate significantly. For instance, a deviation of $0.05 \mathrm{~kg} / \mathrm{hr}$ at $0.5 \mathrm{~kg} / \mathrm{hr}$ and $60 \mathrm{rpm}$ would produce a change of channel fill between 0.288 and 0.352 (equation 1) which will make increase the torque around a $30.4 \%$.

This can be seen as a limit of the equipment behaviour where there is a substantial change in the slope of the curve.

The specific mechanical energy spent in granulation was estimated subtracting the values of the SME used for transport of the dry powder from the values of SME used when liquid was added to the system. Although the transport of dry and wet powder has not the same efficiency, the SME does not take into account this difference since it is calculated as function of the total amount of material introduced in the equipment which is constant in this case. Figure 7a suggests that initially the specific mechanical energy value used for transport of the dry powder is higher than the one used for granulation until it equalises around a channel fill of 0.18 . After that point energy used for granulation becomes predominant until the last channel fill value where transport became predominant again over granulation. The specific mechanical energy used in granulation does not vary as much as the one required from transport that varies from 206 to $36.8 \mathrm{~kJ} / \mathrm{kg}$. Furthermore, comparing figure $7 \mathrm{a}$ and $7 \mathrm{~b}$ shows that after 0.27 channel fill, although the torque required increases dramatically, the specific mechanic energy used in granulation is almost constant. 
International Journal of Pharmaceutics

406 In addition, the specific mechanical energy was studied at channel fill of 0.27 produced by

407 three different conditions (figure 8). It was found that this value was not constant depending 408 on the channel fill and it varied highly depending on the torque requirements. However, the 409 large size of the error bars seems to indicate that the specific mechanical energy has not a 410 constant value along the same conditions of feed rate and screw velocity. The range variation 411 of this parameter reduces highly its potential as process design parameter.

\section{2}

\subsection{Effect of the increase of channel fill and torque in the shear stress.}

413 The CAMES were used to measure the stress experienced by the powder at different channel fills. In figure 9, three different levels of channel fill at two different sets of conditions each (Table 2) are presented. The local stress produced by the transport of the powder through the granulator without liquid addition was consistently in the range 360-490 $\mathrm{kPa}$ which corresponds for $55-70 \%$ of the total shear experienced by the formulation during granulation conditions. This result is consistent with the results obtained in figure 6 for no liquid addition where at channel fills up to 0.270 , the torque required did not have great variations $(0.49-0.68$ N.m) and did not present a linear trend with channel fill. The breakage of the CAMES in this case is due only to the transport of the powder through the equipment since no liquid addition was done at that point. In addition, figure 9 suggests that the local stress experienced in the combined granulation and transport process increases when channel fill increases within channel fill range in figure 9. As the transport only data suggest this is not due to transport, this increase would be due only to granulation which is consequent with the increment in size observed in the PSDs in figure 4. However, with the variability obtained is not possible to confirm this trend and it is only possible to conclude that there is a significant increase in stress due to addition of water to give the granulation process. 
International Journal of Pharmaceutics

429 Granulation using a constant feed rate of $0.5 \mathrm{~kg} / \mathrm{hr}$ and $\mathrm{L} / \mathrm{S}=0.175$ and varying the screws velocity between $40-400 \mathrm{rpm}$ (Table 1) are presented in figure 10 with the local stress plotted against the channel fill with the specific mechanical energy as labels. Interestingly the results suggest that granules experience higher local stresses at a specific range of channel fills and this is not directly related to overall SME input. The points with highest local stresses align to transition to exponential torque rise with increased granulation energy but prior to fully filled barrel.

Nonetheless, it is possible to conclude that all the formulation or powder introduced into the twin screw granulator experienced a total stress between 360 and $1000 \mathrm{kPa}$. Direct comparisons with the literature is not possible due to the change of scale and formulation. However, these values are significantly higher than those found in literature (under $160 \mathrm{kPa}$ ). Further exploration to understand the internal forces of the granules will be required to identify

441 if this disagreement could be due to the lack of size equivalence between formulation and 442 sensors (Pradhan et al., 2017), underestimation of some internal forces experienced by the granules from global estimates (Dhenge et al., 2011) or a direct relationship to change in scale and screw configuration. 
International Journal of Pharmaceutics

447

448

449

450

451

452

453

454

455

456

457

458

459

460

461

462

463

464

465

466

467

468

469

470

\section{CONCLUSIONS}

The applicability of channel fill as a parameter to inform PSD, local stress (via CAMES) and torque was studied. Channel fill fraction used previously for the 16-mm TSG as design tool was shown to be a good predictor of granule PSD shape on 11-mm TSG with superior design potential than the SME and the screw speed. Consequently, the channel fill can be used to scale up and down productions remaining a constant channel fill and configuration. Also, it could increment the functionality of the equipment in environments with high variability in production. In addition, the applicability of the CAMES microparticles in granulation was demonstrated offering a novel way to measure TSG internal stress at a particle scale of scrutiny. It was verified that during granulation, the powder experienced total stresses in a $360-1000 \mathrm{kPa}$ range which was relatively higher than it was expected. A potential local maxima in local stress was observed that doesn't align to high SME input but instead with torque transition caused by channel fill. As well as the same channel fills, the stress experienced by the granules was similar confirming the expectation that granules would have similar morphological properties. Transport of the granules without liquid addition suggested that up to $70 \%$ of the total breakage of the CAMES and up to $86 \%$ of the required torque may not be created by granulation process. Furthermore, it was found that the twin screw granulator does not present a linear relationship between channel fill and torque increasing sharply after a certain point and becoming sensitive to small variations in speed and or fill. Understanding this interplay of local and global behaviour can be critical in both implementation and control of the technology.

\section{ACKNOWLEDGEMENTS}

The authors would like to thank EPSRC and the Doctoral Training Centre in Continuous Manufacturing and Crystallisation (CMAC) for funding this work, grant number $\mathrm{EP} / \mathrm{K} 503289 / 1$. 
International Journal of Pharmaceutics

471 The authors would like to acknowledge that this work was carried out in the CMAC National 472 Facility supported by UKRPIF (UK Research Partnership Fund) award from the Higher 473 Education Funding Council for England (HEFCE) (Grant ref HH13054). Gavin Halbert is 474 funded by Cancer Research UK (C149/A20740).

475 
International Journal of Pharmaceutics

\section{LIST OF FIGURES}

477 Figure 1. Summary of experiments for 11-mm TSG

478 Figure 2. UV calibration of the dye

479 Figure 3. Microscopic images of the CAMES breakage in the shear cell. a) 0.01 b) 0.1 c) 1 d)

$480 \quad 5 \mathrm{rad} / \mathrm{sec}$

481 Figure 4. PSDs depending on the channel fill

482 Figure 5. Comparison of PSDs at different screw velocity at three levels of $\Delta \Phi$.

483 Figure 6. Torque depending on channel fill with and without liquid addition $(n=$ number of 484 repetitions, points $=$ arithmetic mean, error bar $=$ standard deviations)

485 Figure 7. Predominant event depending on Torque a) and Specific mechanical energy b)

486 Figure 8. Specific mechanical energy at channel fill fraction of $0.272(\mathrm{n}>90$, Error bars $=$ 487 Standard deviation calculated as function of the standard deviation of the torque).

488 Figure 9. Local shear stress depending on the channel fill produced (points $=$ arithmetic mean 489 of the two different channel fills, error bars= standard deviation)

490 Figure 10. Local stress at steady state depending on the channel fill $(n=1$, data labels $=$ specific 491 mechanical energy). 
International Journal of Pharmaceutics

493 Table 1. Summary of channel fill and shear stress relationship experiments with (w/) and 494 without (w/o) CAMES.

\begin{tabular}{|c|c|c|c|c|}
\hline Screws velocity (rpm) & Feed rate $(\mathrm{kg} / \mathrm{hr})$ & $\mathbf{L} / \mathbf{S}$ & $\Phi$ & CAMES \\
\hline 400 & 0.5 & 0.175 & 0.068 & $\mathrm{w} /$ and $\mathrm{w} / \mathrm{o}$ \\
\hline 350 & 0.5 & 0.175 & 0.078 & $\mathrm{w} /$ and $\mathrm{w} / \mathrm{o}$ \\
\hline 300 & 0.5 & 0.175 & 0.091 & $\mathrm{w} / \mathrm{o}$ \\
\hline 250 & 0.5 & 0.175 & 0.110 & $\mathrm{w} /$ and $\mathrm{w} / \mathrm{o}$ \\
\hline 200 & 0.4 & 0.175 & 0.137 & $\mathrm{w} / \mathrm{o}$ \\
\hline 150 & 0.5 & 0.175 & 0.183 & $\mathrm{w} /$ and $\mathrm{w} / \mathrm{o}$ \\
\hline 100 & 0.5 & 0.175 & 0.274 & $\mathrm{w} /$ and $\mathrm{w} / \mathrm{o}$ \\
\hline 80 & 0.5 & 0.175 & 0.342 & $\mathrm{w} /$ and $\mathrm{w} / \mathrm{o}$ \\
\hline 60 & 0.5 & 0.175 & 0.457 & $\mathrm{w} /$ and $\mathrm{w} / \mathrm{o}$ \\
\hline 40 & 0.5 & 0.175 & 0.685 & $\mathrm{w} /$ and $\mathrm{w} / \mathrm{o}$ \\
\hline
\end{tabular}

495

496 
International Journal of Pharmaceutics

497 Table 2. Summary of experiments of channel fill at two different levels and shear stress 498 relationship.

\begin{tabular}{|c|c|c|c|}
\hline $\boldsymbol{\Phi}$ & Screws velocity (rpm) & Feed rate (kg/hr) & L/S \\
\hline 0.073 & 150 & 0.2 & 0.175 \\
\hline 0.073 & 400 & 0.53 & 0.175 \\
\hline 0.146 & 150 & 0.4 & 0.175 \\
\hline 0.146 & 400 & 1.06 & 0.175 \\
\hline 0.270 & 150 & 0.74 & 0.175 \\
\hline 0.270 & 400 & 1.98 & 0.175 \\
\hline
\end{tabular}


International Journal of Pharmaceutics

Table 3. Statistical analysis performed to the PSDs at different channel fill.

\begin{tabular}{|c|c|c|c|c|c|c|}
\hline & \multicolumn{2}{|c|}{ F-test } & \multicolumn{3}{c|}{ Anova One-way-HOV } & \\
\hline Channel & F & p- & B-F statistic & df & p- & Significantly \\
different & & & value & No \\
\hline $\mathbf{0 . 0 4 6}$ & 0.749 & 0.693 & - & - & - & No \\
\hline $\mathbf{0 . 0 7 3}$ & 0.755 & 0.700 & - & - & - & No \\
\hline $\mathbf{0 . 1 0 8}$ & - & - & 0.491 & 7 & 0.827 & No \\
\hline $\mathbf{0 . 1 4 7}$ & - & - & 0.855 & 7 & 0.560 & No \\
\hline $\mathbf{0 . 1 9 4}$ & 1.396 & 0.608 & - & - & - & No \\
\hline $\mathbf{0 . 2 7 1}$ & - & - & 1.3 & 8 & 0.304 & \\
\hline
\end{tabular}

501

502 
International Journal of Pharmaceutics

Table 4. Statistical analysis performed to the PSDs at different screw velocity.

\begin{tabular}{|c|c|c|c|c|}
\hline & & \multicolumn{2}{|c|}{ F-test } & \\
\hline Screw speed & $\Delta \Phi$ & F & p-value & Significantly different \\
\hline $\mathbf{4 4 0} \pm \mathbf{6}$ & $\mathbf{0 . 0 3 9} \mathbf{1}^{1}$ & 0.93 & $9.27 \mathrm{E}-1$ & No \\
\hline $\mathbf{3 0 0} \pm \mathbf{6}$ & $\mathbf{0 . 0 3 9}$ & 0.67 & $6.05 \mathrm{E}-1$ & No \\
\hline $\mathbf{4 4 0} \pm \mathbf{6}$ & $\mathbf{0 . 1 2 1}$ & 2.40 & $2.71 \mathrm{E}-1$ & No \\
\hline $\mathbf{1 9 6} \pm \mathbf{6}$ & $\mathbf{0 . 2 2 5}$ & 34.52 & $4.57 \mathrm{E}-6$ & Yes \\
\hline
\end{tabular}

504

505 
International Journal of Pharmaceutics

506

507

508

509

510

511

512

513

514

515

516

517

518

519

520

521

522

523

524

525

526

527

528

529

\section{REFERENCES}

Bigio, D., Pappas, W., Brown II, H., Debebe, B., Dunham, W., 2011. Residence stress distributions in a twin screw extruder, SPE ANTEC Proceedings.

Brandt, S., Brandt, S., 2014. Data analysis, 4th ed. Springer.

Condo, A.C., Kosowski, B.M., 1991. Processing of materials using rupturable microcapsulates containing detection materials. Google Patents.

Dhenge, R.M., Cartwright, J.J., Doughty, D.G., Hounslow, M.J., Salman, A.D., 2011. Twin screw wet granulation: Effect of powder feed rate. Advanced Powder Technology 22, $162-$ 166.

Dhenge, R.M., Cartwright, J.J., Hounslow, M.J., Salman, A.D., 2012. Twin screw wet granulation: Effects of properties of granulation liquid. Powder Technology 229, 126-136.

Dhenge, R.M., Fyles, R.S., Cartwright, J.J., Doughty, D.G., Hounslow, M.J., Salman, A.D., 2010. Twin screw wet granulation: Granule properties. Chemical Engineering Journal 164, $322-329$.

Dhenge, R.M., Washino, K., Cartwright, J.J., Hounslow, M.J., Salman, A.D., 2013. Twin screw granulation using conveying screws: Effects of viscosity of granulation liquids and flow of powders. Powder Technology 238, 77-90.

Djuric, D., Kleinebudde, P., 2008. Impact of screw elements on continuous granulation with a twin-screw extruder. Journal of pharmaceutical sciences 97, 4934-4942.

Djuric, D., Van Melkebeke, B., Kleinebudde, P., Remon, J.P., Vervaet, C., 2009. Comparison of two twin-screw extruders for continuous granulation. European Journal of Pharmaceutics and Biopharmaceutics 71, 155-160.

Godavarti, S., Karwe, M.V., 1997. Determination of Specific Mechanical Energy Distribution on a Twin-Screw Extruder. Journal of Agricultural Engineering Research 67, 277-287. 
International Journal of Pharmaceutics

530 Gorringe, L., Kee, G., Saleh, M., Fa, N., Elkes, R., 2017. Use of the channel fill level in

531 defining a design space for twin screw wet granulation. International journal of

532 pharmaceutics 519, 165-177.

533 ISO 13322-1:2014, 2014. Particle size analysis - Image analysis methods - Part 1: Static

534 image analysis methods.

535 Keleb, E.I., Vermeire, A., Vervaet, C., Remon, J.P., 2002. Continuous twin screw extrusion

536 for the wet granulation of lactose. International Journal of Pharmaceutics 239, 69-80.

537 Keleb, E.I., Vermeire, A., Vervaet, C., Remon, J.P., 2004. Twin screw granulation as a

538 simple and efficient tool for continuous wet granulation. International Journal of

539 Pharmaceutics 273, 183-194.

540 Lee, K.T., Ingram, A., Rowson, N.A., 2012. Twin screw wet granulation: The study of a

541 continuous twin screw granulator using Positron Emission Particle Tracking (PEPT)

542 technique. European Journal of Pharmaceutics and Biopharmaceutics 81, 666-673.

543 Lute, S.V., Dhenge, R.M., Salman, A.D., 2018. Twin Screw Granulation: An Investigation of 544 the Effect of Barrel Fill Level. Pharmaceutics 10.

545 MacLeod, C.S., Muller, F.L., 2012. On the fracture of pharmaceutical needle-shaped crystals

546 during pressure filtration: case studies and mechanistic understanding. Organic Process

547 Research \& Development 16, 425-434.

548 Mendez Torrecillas, C., Gavin Halbert, Dimitrios Lamprou, 2017. A novel methodology to 549 study the polymodal particle size distributions produced during continuous wet granulation.

550 International Journal of Pharmaceutics.

551 Mendez Torrecillas, C., Halbert, G., Lamprou, D., 2017. A novel methodology to study

552 polymodal particle size distributions produced during continuous wet granulation. 
International Journal of Pharmaceutics

553

554

555

556

557

558

559

560

561

562

563

564

565

566

567

568

569

570

571

572

573

574

575

576

577

Mundozah, A.L., Cartwright, J.J., Tridon, C.C., Hounslow, M.J., Salman, A.D., 2018.

Hydrophobic/hydrophilic powders: Practical implications of screw element type on the reduction of fines in twin screw granulation. Powder Technology.

O'Brien, R.G., 1979. A General ANOVA Method for Robust Tests of Additive Models for Variances. Journal of the American Statistical Association 74, 877-880.

O'brien, R.G., 1981. A simple test for variance effects in experimental designs. Psychological Bulletin 89, 570.

Osorio, J.G., Sayin, R., Kalbag, A.V., Litster, J.D., Martinez-Marcos, L., Lamprou, D.A., Halbert, G.W., 2017. Scaling of continuous twin screw wet granulation. AIChE Journal 63, 921-932.

Pappas, W., Brown Ii, H., Fukuda, G., Adnew, R., Bigio, D., 2012. Variable strength stress bead analysis in a twin screw extruder. SPE ANTEC Tech. Papers.

Pradhan, S.U., Sen, M., Li, J., Litster, J.D., Wassgren, C.R., 2017. Granule breakage in twin screw granulation: Effect of material properties and screw element geometry. Powder Technology 315, 290-299.

Seem, T.C., Rowson, N.A., Ingram, A., Huang, Z., Yu, S., de Matas, M., Gabbott, I., Reynolds, G.K., 2015. Twin screw granulation-A literature review. Powder Technology $276,89-102$.

Silva, A.F., Vercruysse, J., Vervaet, C., Remon, J.P., Lopes, J.A., De Beer, T., Sarraguça, M.C., 2018. Process monitoring and evaluation of a continuous pharmaceutical twin-screw granulation and drying process using multivariate data analysis. European Journal of Pharmaceutics and Biopharmaceutics 128, 36-47.

The MathWorks Inc, 2013. Release, Matlab. Inc., Natick, Massachusetts, United States 488. Thompson, M., 2014. Twin screw granulation-review of current progress. Drug development and industrial pharmacy, 1-9. 
International Journal of Pharmaceutics

578 Thompson, M.R., Sun, J., 2010. Wet Granulation in a Twin-Screw Extruder: Implications of

579 Screw Design. Journal of Pharmaceutical Sciences 99, 2090-2103.

580 Van Melkebeke, B., Vervaet, C., Remon, J.P., 2008. Validation of a continuous granulation

581 process using a twin-screw extruder. International journal of pharmaceutics 356, 224-230.

582 Vercruysse, J., Burggraeve, A., Fonteyne, M., Cappuyns, P., Delaet, U., Van Assche, I., De

583 Beer, T., Remon, J.P., Vervaet, C., 2015. Impact of screw configuration on the particle size

584 distribution of granules produced by twin screw granulation. International journal of

585 pharmaceutics 479, 171-180.

586 Verstraeten, M., Van Hauwermeiren, D., Lee, K., Turnbull, N., Wilsdon, D., am Ende, M.,

587 Doshi, P., Vervaet, C., Brouckaert, D., Mortier, S.T., 2017. In-depth experimental analysis of 588 pharmaceutical twin-screw wet granulation in view of detailed process understanding.

589 International journal of pharmaceutics 529, 678-693.

590 Wang, Y., Rodríguez de Gil, P., Chen, Y.-H., Kromrey, J.D., Kim, E.S., Pham, T., Nguyen,

591 D., Romano, J.L., 2017. Comparing the performance of approaches for testing the

592 homogeneity of variance assumption in one-factor ANOVA models. Educational and

593 psychological measurement 77, 305-329. 